\title{
Ants Can Acquire Some Serial Recognition
}

\author{
Marie-Claire Cammaerts ${ }^{1} \&$ Roger Cammaerts ${ }^{2}$ \\ ${ }^{1}$ Independent researcher, retired from the Biology of Organisms Department, University of Brussels, Belgium \\ ${ }^{2}$ Independent researcher, retired from the Natural and Agricultural Environmental Studies Department (DEMNA) \\ of the Walloon Region, Belgium \\ Correspondence: Marie-Claire Cammaerts, Independent researcher, retired from the Biology of Organisms \\ Department, University of Brussels, Belgium. Tel: 32-2673-4969. E-mail: mtricot@ulb.ac.be, \\ mccammaerts@gmail.com
}

Received: March 19, 2018

Accepted: March 27, 2018

Online Published: March 30, 2018

doi:10.5539/ijb.v10n2p31

URL: https://doi.org/10.5539/ijb.v10n2p31

\begin{abstract}
Aiming to define the ants' cognitive abilities, we examined if they could learn a correct sequence and recognize it among others made of the same elements but otherwise ordered. We first trained them to a sequence of three elements. They could recognize the correct sequence from the two wrong sequences, reaching a score of $66.9 \%$ after 8 training days, what was a rather low though statistically significant score. When trained to a sequence of 4 elements, the ants could also recognize the correct sequence from three wrong ones, reaching the low though statistically significant score of $51.2 \%$ in 8 training days. In this second experiment, the ants appeared to better learn the two last elements of the sequence (those directly associated with the reward) than the two first ones. This was in agreement with our previous finding that ants could learn a behavioral sequence only if trained according to a backwards chaining, i.e. if firstly presented with the element associated to the reward. Such kind of learning is in fact some operant conditioning, and apparently differs from what occurs in vertebrates since the latter learn a behavioral sequence under a backward as well as a forward method, and better remember not only the last but also the first element of a series. The neural mechanism(s) underlying serial recognition may thus at least partly differ between vertebrates and invertebrates.
\end{abstract}

Keywords: conditioning, learning, Myrmica sabuleti, sequence of elements, visual perception

\section{Introduction}

Ants are among the most evolved social insects and have many cognitive abilities. Some are innate, other ones are learned during their first year of life (Passera \& Aron, 2005; Hölldobler \& Wilson, 1990; M. C. Cammaerts \& D. Cammaerts, 2014; M. C. Cammaerts \& R. Cammaerts, 2015), but they can acquire new ones in the course of experienced events. For instance, they can expect the location and the time of subsequent food deliveries on the basis of previous food deliveries (M. C. Cammaerts \& R. Cammaerts, $2016 \mathrm{a}, \mathrm{b}$ ). They can solve simple problems (Cammaerts, 2017 a), learn new behavior (Cammaerts, 2017 b), learn a behavioral sequence (Cammaerts, 2018 b) but cannot use sensu stricto tools (Cammaerts, 2018 a). With these two last works, we are approaching exactly defining the extent of the ants' cognitive capabilities. For going on with such an approach, we aimed to examine if ants can learn to recognize (i.e. to react to) a given sequence presented together with other possible ones made of the same elements but otherwise ordered. In other words, we wanted to study if ants can acquire serial recognition. Moreover, if ants detain this capability, we should research how they proceed to learn a given sequence and recognize it among others made of the same, but otherwise ordered elements. Do they do so like vertebrates do, by learning each association between an element and the following one (Pearce, 2008, see below) or do they proceed otherwise?

Effectively, it has been shown that birds, monkeys and humans learn (and later on recognize) a given sequence of elements by learning and memorizing (using their long-term memory) the association between the first element and the following one, then by learning the association of the second element of the sequence to the third one and again memorizing this association in their long-term memory, and so on until the last association, which is thus the last memorized one (Weisman, Wasserman, Dodd \& Larew, 1980; Terrace, 1986; Roiblat, Bever, Helweg, \& Harley, 1991; Balleine, Garner, Gonzalez, \& Dickinson, 1995). On the basis of the latter cited works, and of the brilliant experiments of Sands and Wright (1980) and of Wrigth, Santiago, Dands, Kendrick and Cook (1985), it could be admitted that the vertebrates better learn the association between the first and the second elements, as well 
as the association between the fore last and the last elements of the sequence. Associations between intermediate elements are generally less well memorized. The ethologists have named the graph, describing the quality of the memorization of the successive associations between the elements of a sequence, a ' $U$ shape graph', since the beginning and the end of the sequence are generally better memorized than the middle part. Such a ' $U$ shape graph' is obtained when experimenting on birds, monkeys and humans. Therefore, the cerebral mechanisms used by these vertebrates for memorizing a sequence are probably similar. Note also that serial recognition is impacted by drugs consumption (Castro, 1995, 1997).

To come back to ants, for investigating the mechanism they use for learning a sequence, they must be presented with a sequence containing at least four elements, so that there is a first, a middle and a last association to memorize. As we did not know if they could effectively learn a sequence and distinguish it from other ones made of same elements, they had to be firstly experimented in presence of a sequence made of three elements.

Collett, Fry, and Whener (1993) have made the three following observations on bees. These hymenoptera appeared to be able to learn a motor sequence: they can reproduce the same succession of short trajectories. However, additional experiments showed that they can navigate the whole trajectory otherwise (according to another succession of short trajectories). In fact, further experiments have demonstrated that, in fine, bees learn essentially each element of the sequence, more than the entire sequence itself, and perform these different elements in any order, or more precisely in the more rentable order. This latter behavior does not exclude that, in a stable situation, bees are nevertheless capable to learn a motor sequence. The ant Gigantiops destructor has also been shown to be able to memorize a motor sequence: the workers perfectly reproduced the trajectory made of a series of given short trajectories (Macquart, Latil, \& Beugnon, 2008).

The present work deals with another kind of sequence learning than those here above related, investigating on the ants' putative ability in memorizing and later on recognizing a given sequence of three then four elements among other sequences made of exactly the same elements but presented in different orders, and, if they detain this ability, hypothesizing about the cerebral mechanisms underlying this putative ability.

\section{Material and Methods}

\subsection{Collection and Maintenance of Ants}

We worked on two colonies of M. sabuleti collected at Rédange (France, Moselle department) in May 2017, which contained about 500 workers, brood and one queen. Each colony was maintained in glass tubes half filled with water, a cotton plug separating the ants from the water. These tubes were deposited in a tray $(34 \mathrm{~cm} \times 23 \mathrm{~cm} \times 4$ $\mathrm{cm}$ ), the borders of which were covered with talc to prevent escaping. The ants were fed with an aqueous solution of sugar given ad libidum in small cotton plugged tubes and with cut Tenebrio molitor larvae (Linnaeus, 1758) given three times a week. The temperature equaled $20-21^{\circ} \mathrm{C}$, the relative humidity about $80 \%$, the intensity of lighting 330 lux while working on ants and 5-120 lux during other time periods, and the electromagnetic field 2$3 \mu \mathrm{W} / \mathrm{m}^{2}$. The workers are here often named nestmates, as done by researchers on social insects.

\subsection{Serial Recognition, the Sequence being Made of Three Elements}

\subsubsection{Training the Ants}

Colony A and colony B were maintained as usually but each colony had two nest tubes and two sugar tubes at their disposal (Fig. 1, left part). For each colony, in front of each of these four tubes, a piece of paper was set (extra strong paper, Clairefontaine ${ }^{\circledR}, 1.5 \mathrm{~cm} \times 4.5 \mathrm{~cm}$ for those in front of the nest tubes; $1.2 \mathrm{~cm} \mathrm{x} 3 \mathrm{~cm}$ for those in front of the sugar tubes) made of three identically long but differently colored parts, the part in contact with the tube entrance being blue, the middle part green, and the more distant from the tube entrance yellow (Fig. 1, left part). Myrmica sabuleti workers have been shown to be able to discriminate the colors (Cammaerts, 2007). During four days, six times per day, we counted the ants of colony A and colony B moving on as well as being very near the four correct sequences of colors present in their tray. The sum of these twelve ( $6 \times 2$ colonies) daily counts was established each day (Table 1, upper part, column 2), and finally the mean of all the counts was calculated (Table 1, upper part, column 3). This last value represented the mean number of ants present at any time on any four correct sequences of colored papers provided to the two colonies.

\subsubsection{Testing the Ants}

Four tests were performed, on days $5,6,7$, and 8 , the ants being still trained during these four days. To perform a test on a colony, 30 ants of that colony were momentarily transferred into a tray $(15 \mathrm{~cm} \mathrm{x} 30 \mathrm{~cm} \mathrm{x} 4 \mathrm{~cm})$ into which 6 tubes and 6 colored pieces of paper had previously been set. The six tubes were three potential nest tubes and three small cotton plugged tubes similar to the ants' sugar tubes but without sugar. In front of the three former as well as the three latter tubes, a piece of paper with three colored parts was deposited. The colored parts had the 
same dimension as those used for training the ants but they were new (and thus not chemically marked by the ants) and the colors were partially differently ordered. For the three potential nest tubes as well as for the three small tubes, one of the tubes had in front of its entrance a piece of paper with colors ordered as the three parts used for training the ants (yellow, green, blue successively towards the entrance), another tube had successively a blue, a yellow and a green parts, and the third tube had successively a green, a blue and a yellow parts (Fig. 1, right part; Fig. 2). During 10 minutes, we counted at the end of each $30 \mathrm{sec}$ time period (total number of counts $=20$ ), the ants present on as well as very near each of the 12 presented colored pieces of paper ( 6 pieces of paper x 2 colonies). The numbers of ants counted on or near each of the three different sequences of colored papers were then added, and the results obtained for the two colonies were summed, obtaining so three final numbers (Table 1, lower part, column 2). This allowed calculating the proportion of ants seen on or very near the 'correct' colored sequence (= that used for training the ants). The three final numbers obtained (one for each kind of sequence) were statistically compared to those expected if ants randomly went on or very near any of the three different presented sequences (Table 1, lower part, column 3 ) using the non-parametric $\chi^{2}$ goodness-of-fit test (Siegel \& Castellan, 1989).
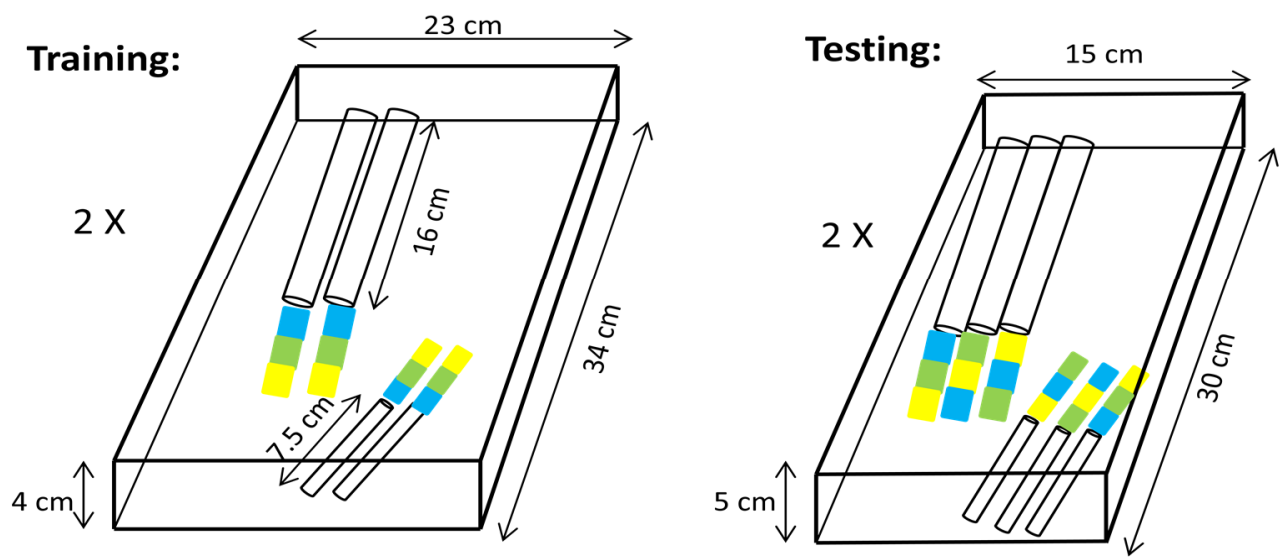

Figure 1. Schematic representation of the experimental design used for examining if ants could recognize a correct sequence made of three elements from two other wrong ones

Details and more dimensions are given in the text. Results can be found in the text and in Table 1. ' 2 X' signifies that such an experimental design was set for each two used colonies.
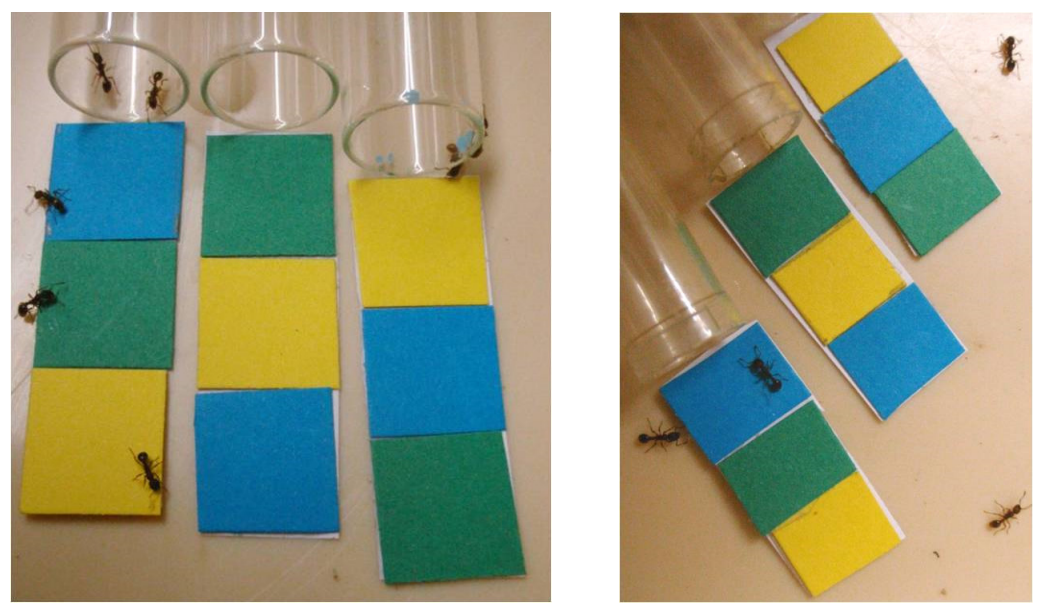

Figure 2. Ants tested in front of three sequences, 'yellow, green, blue' being the correct sequence (i.e. that to which the ants were trained)

The left photo shows the sequences set in front of potential nest tubes; the right photo, the sequences set in front of potential sugar water tubes. The ants effectively somewhat preferred the correct sequence. They could thus acquire some serial recognition with a rather low final score (see Table 1), when the series contained only 3 elements. 


\subsection{Serial Recognition, the Sequence being Made of Four Elements}

\subsubsection{Training of the Ants}

In order to avoid that the experiment using sequences of three elements influence the experiment described here below using sequences of four elements, one week elapsed between the two experiments, and the elements used in the second experiment were completely different from those used in the first experiment. We thus no longer used pieces of colored papers laid on the ground, but visual cues $M$. sabuleti workers are able to distinguish. Our works on the ants' visual perception have shown, among others, that this species can discriminate vertical, horizontal, and differently oriented segments (as well as different lengths, wideness, numbers, and forms) (Cammaerts, 2008). They are very sensitive to the blue color, even if lighting is low (Cammaerts, 2007). Each colony had its own sequences. We presented the ants with a sequence made of four blue cues, i.e. a vertical segment, a horizontal one, a segment turned at $45^{\circ}$ to the left and a segment turned at $45^{\circ}$ to the right, this sequence being considered as correct. These segments were made of blue paper (extra strong paper, Clairefontaine ${ }^{\circledR}$ ), and were glued each one onto a piece of white extra strong paper staying vertically on a horizontal base (Fig. 3, left part). Each sequence of four elements was tied to a parallelepiped piece of strong paper for avoiding any accidental displacement or relocation of the different elements while caring of the ants (see photos on Fig. 4). Exactly as for the experiment using three elements, during four days, six times per day, we counted the ants of colony A and colony B moving on or very near the four correct sequences present in their tray. The sum of these twelve $(6 \times 2$ colonies) daily counts was established each day (Table 2, upper part, column 2), and finally the mean of all the counts was calculated (Table 2, upper part, column 3). This last value represented the mean number of ants present at any time on any four correct sequence provided to the two colonies.

\subsubsection{Testing of the Ants}

Four tests were performed, on days 5,6,7, and 8, the ants being still trained during these four days. To perform a test on a colony, 30 ants of that colony were momentarily transferred into a tray $(15 \mathrm{~cm} \mathrm{x} 30 \mathrm{~cm} \mathrm{x} 4 \mathrm{~cm})$ into which 8 tubes and 8 sequences of blue elements had been set. The eight tubes were four potential nest tubes and four small tubes. In front of the four former as well as the four latter tubes, a sequence of four blue elements was set, one sequence being the correct one, the three other ones being a wrong sequence, i.e. made of the four identical elements but differently ordered. In order to detect if ants better learned the first and/or the last succession of elements than the middle one, we used the correct sequence (vertical, horizontal, oriented to the left, oriented to the right segments), as well as the sequence vertical, horizontal, oriented to the right, oriented to the left segments, the sequence oriented to the right, horizontal, oriented to the left, vertical segments, and the sequence horizontal, vertical, oriented to the left, oriented to the right segments. A schema of such test sequences is shown in Fig. 3, right part, and photos of tests are shown in Fig. 4. Exactly as for the experiment using three elements, for making a test, during 10 minutes, we counted at the end of each $30 \mathrm{sec}$ time period (total number of counts $=20$ ), the ants present on or very near each presented sequence of elements. We then added the numbers of ants counted for each four different sequences, obtaining thus four final numbers. Finally, we summed the results obtained for the two used colonies (Table 2, lower part, column 2). This allowed calculating the proportion of ants seen on or very near the 'correct' sequence (= that used for training the ants). The four final numbers obtained (one for each four sequence) were statistically compared to those expected if ants randomly went on or very near any of the four presented sequences (Table 2, lower part, column 3) using the non-parametric $\chi^{2}$ goodness-of-fit test (Siegel \& Castellan, 1989). 


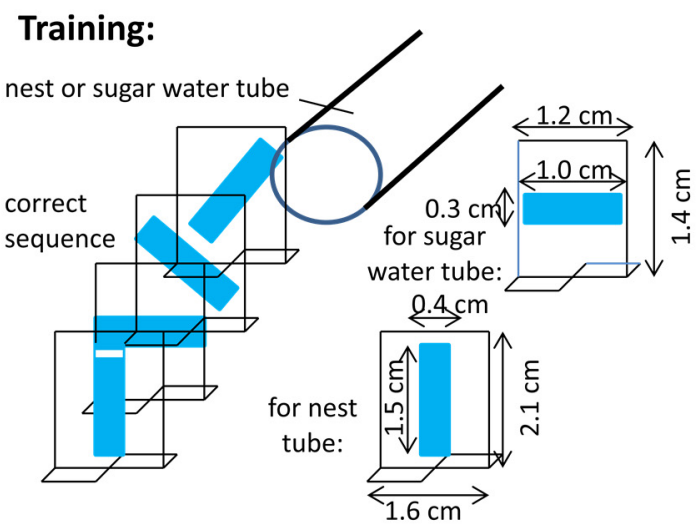

\section{Testing:}

In front of 4 potential nest and sugar water tubes, the sequences were:
$1,2,3,4$ correct
1,2 correct
2, 3 correct 3,4 correct
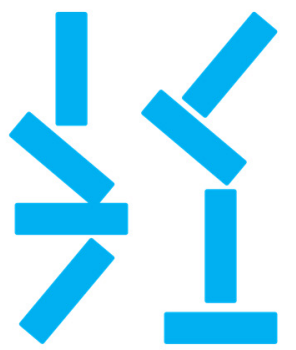

Figure 3. Schematic representation of the experimental design used for examining if ants could recognize a correct sequence made of four elements from three other wrong ones

Details are given in the text. Results can be found in the text and in the Table 2. Note that each colony had its own experimental apparatus. Photos of the experiment are shown in Figure 4.
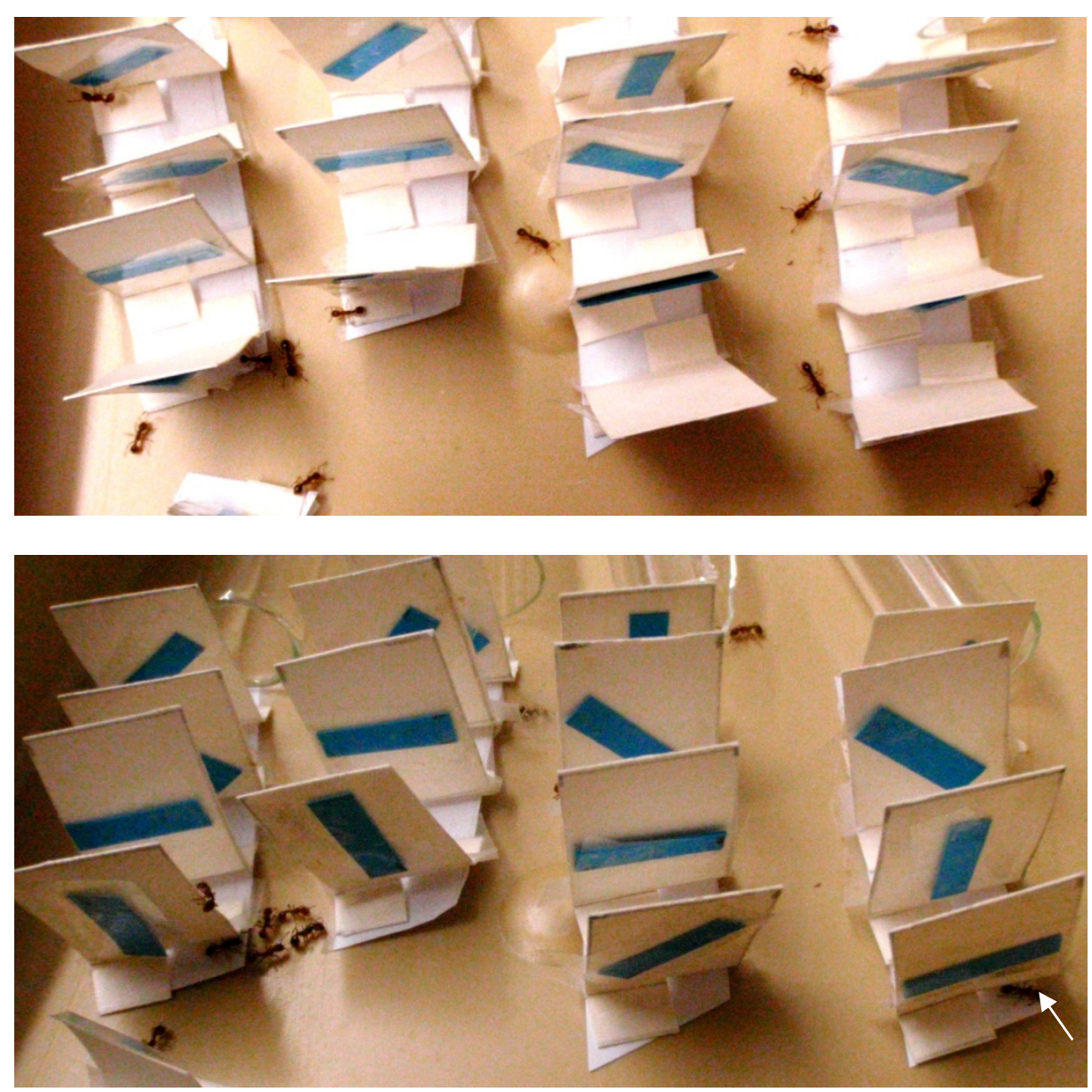

Figure 4. Ants of colony A (upper photo) and colony B (lower photo) tested in front of four sequences made of four elements, that located on the left being the correct one (that to which ants were trained)

The ants were effectively more numerous on the correct sequence (upper photo: 4 ants, lower photo: 6 ants). Among the three other (wrong) sequences, the ants chose that having the two last elements correct (the sequence located on the right on the photos) (upper photo: 5 ants, lower photo: 1 ant (white arrow)). The ants could thus learn a sequence of 4 elements, remembering better the last elements of the sequence than the first ones. 


\section{Results}

\subsection{Serial Recognition, the Sequence Being Made of Three Elements}

Photos of the experiment are shown in Figure 2.

After having been trained during four days in presence of the sequence 'yellow, green, blue' (Table 1, upper part; meanly 2.69 ants were at any time present along the sequence), and while being still trained to this sequence, the ants somewhat preferentially walked onto that sequence when tested in front of it and the two other possible ones (78 ants vs 29 and 33; Table 1, lower part, line 1). Even if the ants' score was low (55.7\% of correct responses), such a result already statistically differed from what would have been obtained if ants went randomly walking on the three presented sequences $\left(\chi^{2}=31.76, \mathrm{df}=2, \mathrm{P}<0.001\right)$. On the following day (so, after one more training day), 103 ants chose the correct sequence, compared to 35 and 43 choosing the two other 'wrong' ones (Table 1, lower part, line 2). This corresponded to $56.9 \%$ of correct responses, a result statistically different from a random ants' choice of the three sequences $\left(\chi^{2}=45.87, \mathrm{df}=2, \mathrm{P}<0.001\right)$. During the third test (so, after a total of 7 training days), the ants reached a score of $63.2 \%$ of correct responses (127 correct responses $v s 42$ and 32 wrong ones), a result highly statistically different from a random ants' choice of each sequence (Table 1 , lower part, line $3 ; \chi^{2}=$ $81.34, \mathrm{df}=2, \mathrm{P}<0.001)$. After a total of 8 training days, the number of ants which chose the correct sequence equaled 148, and the number of ants which chose the wrong ones equaled 32 and 41 (Table 1, lower part, line 4). This corresponded to a score of $66.9 \%$, a result again highly significant $\left(\chi^{2}=113.0, \mathrm{df}=2, \mathrm{P}<0.001\right)$.

The ants reached thus, over their 5 to 8 training days, the successive scores of $55.7 \%, 56.9 \%, 63.2 \%$ and $66.9 \%$. Their learning increased thus by $1.2 \%$ during their training day 6 , by $6.3 \%$ during their day 7 , and by $3.7 \%$ during their day 8. In the same way, the values of $\chi^{2}$ associated with the results obtained from day 5 to day 8 increased from 31.76 to 113.0 (Table 1, lower part, column 4). Such an increase of correct responses score was typically that of a conditioning acquisition, with, in the present case, a low final score. We could thus conclude that ants (or more precisely M. sabuleti workers) could distinguish from one another three sequences made of the same elements, but otherwise ordered, could learn to react to a given sequence, and thus to respond to it when being in the presence of the three sequences, and acquired this ability probably though operant conditioning. Briefly, the experimented ants could acquire some serial recognition, of rather poor quality, when trained to a sequence of only three elements.

Could M. sabuleti workers distinguish from one another four sequences made of four elements differently ordered? If they did so, did they better learn the succession $1^{\text {rst }}-2^{\text {nd }}$ and $3^{\text {rd }}-4^{\text {th }}$ elements than the succession $2^{\text {nd }}-3^{\text {rd }}$ elements as do monkeys, birds, and humans, or did they learn a sequence otherwise than these vertebrates (f.i. as a whole)? For trying responding to these two questions, we have set up a novel experiment implying 4 sequences made of four identical elements but differently ordered (see following paragraph).

Table 1. Ants' recognition of a correct sequence made of 3 elements from two wrongs

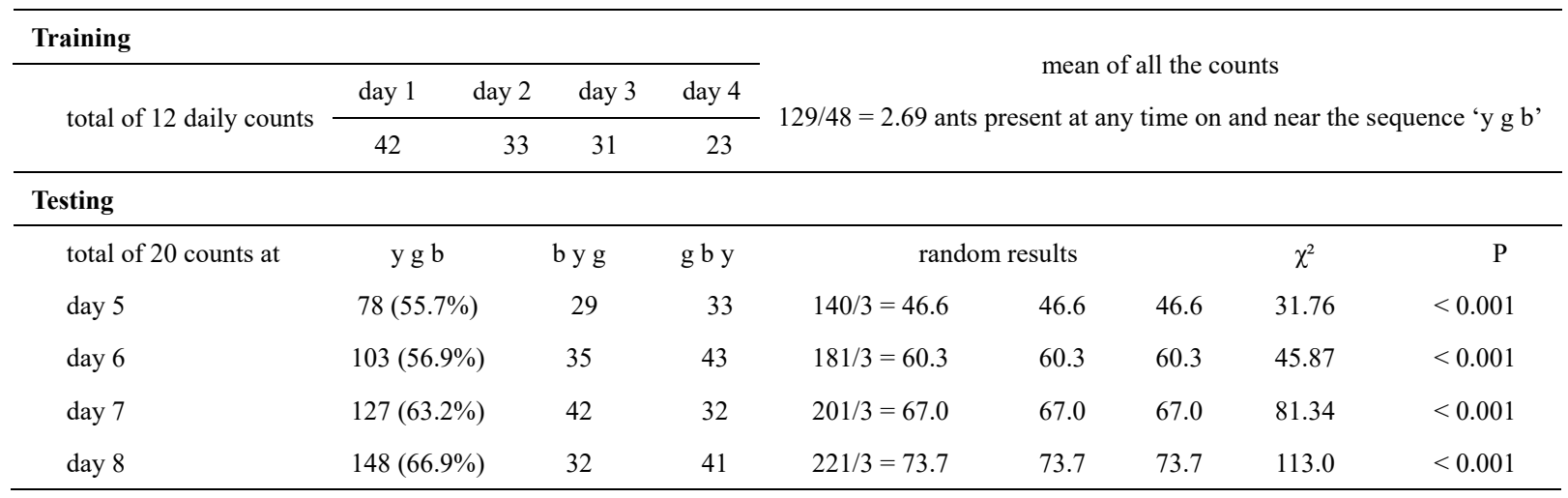

The experimental design is presented in Fig. 1; photos of the experiment are shown in Fig. 2, and details are given in the text. Abbreviations: y g b = yellow, green, blue: the correct sequence; $\mathrm{b}$ y $\mathrm{g}=$ blue, yellow, green: a wrong sequence; $\mathrm{g} b \mathrm{y}=$ green, blue, yellow: a wrong sequence. Briefly, progressively over time, the ants became more numerous on the correct sequence than on the other ones (from 78 i.e. $56 \%$ until 148 i.e. $67 \%$ in four days). 
Table 2. Ants' recognition of a correct sequence made of 4 elements from three wrongs

\begin{tabular}{|c|c|c|c|c|c|c|c|c|c|c|}
\hline \multicolumn{5}{|l|}{ Training } & \multicolumn{6}{|c|}{ mean of all the counts } \\
\hline \multirow{2}{*}{ total of 12 daily counts } & day 1 & day 2 & day 3 & day 4 & \multirow{2}{*}{\multicolumn{6}{|c|}{$157 / 48=3.27$ ants present at any time along the sequence ' $\mathrm{v} \mathrm{h} 1 \mathrm{r}$ ' }} \\
\hline & 47 & 31 & 38 & 41 & & & & & & \\
\hline \multicolumn{11}{|l|}{ Testing } \\
\hline total of 20 counts at & $\mathrm{vh} 1 \mathrm{r}$ & v h r 1 & $\mathrm{rhlv}$ & $\mathrm{h} v 1 \mathrm{r}$ & & $\mathrm{m}$ resu & & & $\chi^{2}$ & $\mathrm{P}$ \\
\hline day 5 & $107(44.9)$ & 26 & 27 & 78 & $238 / 4=59.5$ & 59.5 & 59.5 & 59.5 & 80.28 & $<0.001$ \\
\hline day 6 & $135(42.2)$ & 43 & 60 & 122 & $360 / 4=80.0$ & 80.0 & 80.0 & 80.0 & 81.95 & $<0.001$ \\
\hline day 7 & $147(51.2)$ & 17 & 42 & 81 & $287 / 4=71.8$ & 71.8 & 71.8 & 71.8 & 134.1 & $<0.001$ \\
\hline day 8 & $152(51.2)$ & 28 & 35 & 82 & $297 / 4=74.3$ & 74.3 & 74.3 & 74.3 & 131.7 & $<0.001$ \\
\hline
\end{tabular}

The experimental design is presented in Fig. 3; photos are shown in Fig. 4, and details are given in the text. Abbreviations: $\mathrm{v}=$ vertical segment, $\mathrm{h}=$ horizontal segment, $\mathrm{l}=$ oblique segment with its upper part to the left, $\mathrm{r}=$ oblique segment with its upper part to the right. The correct sequence was: $\mathrm{v} \mathrm{h} 1 \mathrm{r}$. Over time, the ants became more numerous in moving along the correct sequence than along the 3 other ones (from 107 i.e. $45 \%$ until 152 i.e. $51 \%$ in four days).

\subsection{Serial Recognition, the Sequence being Made of Four Elements}

Photos of tested ants are shown in Figure 4.

During their four training days, meanly 3.27 ants moved at any time along the sequence to be learned (Table 2, upper part). After the four training days, at day 5 , the ants moved somewhat more often along the correct sequence than along the three other ones. The proportion of ants correctly responding was weak (45\%), although this result statistically differed from a random moving of the ants along the four presented sequences $\left(\chi^{2}=80.28, \mathrm{df}=3, \mathrm{P}<\right.$ 0.001). Regarding the ants' moving along the three wrong sequences, the ants appeared to be slightly more numerous along the sequence the two last elements of which were in the correct order than along the two other sequences: 78 vs 26 and 27. These three numbers statistically differed from the numbers expected (43.7) if ants randomly moved along the three wrong sequences $\left(\chi^{2}=40.99, \mathrm{df}=2, \mathrm{P}<0.001\right)$. These results are summarized in Table 2, lower part, line 1.

At their sixth training day, when tested in front of the four different sequences for the second time, the ants again essentially moved along the correct sequence $(42.2 \%$ of the ants did so), a result statistically different from a random moving along each four sequences (i.e. 80 ants along each sequence) $\left(\chi^{2}=81.95, \mathrm{df}=3, \mathrm{P}<0.001\right)$. The second most visited sequence was, once more, the fourth one with $33.9 \%$ of the ants doing so. This result also statistically differed from that due to a random choice by the ants of each of the three wrong sequences (i.e. 75 ants along each of these three sequences) $\left(\chi^{2}=46.10, \mathrm{df}=2, \mathrm{P}<0.001\right)$. Results are briefly given in Table 2 , lower part, line 2. Until this experimental step, the results recorded on colonies A and B, as well as during the first and the second tests, were in agreement.

In the course of the third test, on their seventh training day, the ants had a pronounced tendency to move along the correct sequence ( $51.2 \%$ of them did so), and a somewhat high tendency to move along the wrong sequence the two last elements of which were correct ( $28.2 \%$ of them did so). The wrong sequence with the second and the third elements correct was chosen by $14.6 \%$ of the ants; that with the first and the second elements correct was chose by $5.9 \%$ of the ants. The ants' preference for the correct sequence among the four ones presented was statistically significant $\left(\chi^{2}=134.14, \mathrm{df}=3, \mathrm{P}<0.001\right)$; their preference for the sequence with the two last elements correct among the three wrong sequences was also statistically significant $\left(\chi^{2}=44.58, \mathrm{df}=2, \mathrm{P}<0.001\right)$. The numerical results are briefly related in Table 2 , lower part, line 3 . Note that the values of $\chi^{2}$ here obtained were higher than those obtained when analyzing the results of the two previous tests. The ants' learning of the sequence continuously provided along their training increased thus over the training time.

In the course of the fourth test, made at the ants' eighth training day, these ants were, once more, the most numerous in moving along the correct sequence (51.2\% moved there), were also very numerous along the sequence the two last elements of which were correctly ordered (27.6\% of the ants moved there), less numerous along the wrong sequence the second and the third elements of which were correct ( $11.8 \%$ of the ants moved there), and the less numerous in moving along the wrong sequence the first and the second elements of which were correct (9.4\% of the ants moved there). These proportions were very similar (nearly identical) to those obtained in the 
course of the third test, what allowed concluding that ants have reached their maximum score of learning. The fact that they essentially chose the correct sequence among the four presented was statistically significant $\left(\chi^{2}=131.69\right.$, $\mathrm{df}=3, \mathrm{P}<0.001)$. Their choice, among the three wrong sequences, of that with the two last elements correct was also significant $\left(\chi^{2}=35.70, \mathrm{df}=2, \mathrm{P}<0.001\right)$. These numerical results are briefly given in Table 2 , lower part, line 4. Note that the value of $\chi^{2}$ associated with the ants' choice of the correct sequence was not higher than that obtained during the third test (131.69 vs 134.14): the ants have thus effectively reached their maximum learning score. In the same way, the value of $\chi^{2}$ associated with the ants' choice, among the wrong sequences, of that with the two last elements correct was also not higher and even lower than that obtained in the course of the third test (35.70 vs 44.57): the ants have thus obviously reached their maximum score of learning the presented sequence.

The different proportions of ants moving along the four presented sequences during the tests allowed presuming the mechanism according to which the ants acquired their serial recognition. This is explained is the following section.

\subsection{Possible Mechanism Underlying the Ants' Serial Recognition}

The results obtained on ants differed from those obtained on vertebrates: with ants, the sequence that had the two first elements correct was not at all better learned than the other sequences; it was even the less well chosen. We may cautiously advance that ants firstly learned the element located just before the reward (i.e. the entrance of the nest or of the sugar water tube) which was (see the Figure 4) the last element of the sequence. After that, the ants may have learned the element located just before the last one (this last one being associated with the reward), that element being the third one of the sequence (see again the Figure 4). Thereafter, the ants learned in the same way the second element of the sequence, and finally the first one, these two elements being thus the less well learned (memorized) of the sequence. In fact, the ants learned and memorized a sequence made of several elements according to operant conditioning, the last element of the sequence (that immediately followed by the reward) being the first and the better learned, and the first element of the sequence (that not directly associated with a reward) being the last and less learned one. This presumption is in agreement with what we obtained while examining chaining learning on the same ants: the ants could acquire such learning only according to a backward method, i.e. when the first presented element was that directly associated with the reward i.e. the last element of the sequence (Cammaerts, 2018 b). The difference we here observed for serial recognition between ants and vertebrates also appeared for chaining learning: the vertebrates acquire 'chaining learning' when trained according to a backward as well as to a forward method. They are thus not obliged to be rewarded after their first response in order to progressively learn the proposed sequence; they can use their first response as a stimulus for giving the following response, a behavioral trait that ants apparently have not. The cerebral process according to which insects (at least ants) on one hand and vertebrates on the other hand acquire serial recognition (present work) and chaining recognition (previous work) differs. Ants firstly and better memorized the last element(s) easily associated to the reward; vertebrates memorized essentially the first (not directly associated to the reward) but also the last element of the sequence.

\section{Discussion}

We have thus shown that ants (at least $M$. sabuleti workers) can memorize, to some extent, a sequence of elements and distinguish it from other sequences made of the same elements but differently ordered. We have also shown that the ants acquire their learning through operant conditioning, since they remember as a priority, the last elements(s) of the sequence, i.e. those the most directly associated with the reward. Except this underlying operant conditioning process, we know little about the neuronal mechanism(s) allowing ants acquiring serial recognition.

While nearly no research has been made on insects' serial recognition, many ones have been performed on vertebrates, above all on children. However, the exact neuronal mechanism(s) underlying that ability in these vertebrates have not yet been elucidated. The initially emitted hypothesis (obtaining a ' $U$ shape curve', see the 'Introduction' section) was even not always confirmed by novel experiments, for instance by those of Farrell and McLaughlin (2007). Also, some rewarding might help acquiring serial recognition, since pleasant elements are better memorized than neutral ones (Monnier \& Syssaun, 2008). No doubt that research will continue on this topic in vertebrates. As for the invertebrates, and essentially evolved insects such as ants, bees, wasps and bumblebees, experiments should be conducted for bringing information on their ability in acquiring serial recognition, and in case of such an acquisition, on the underlying processes. We aim to participate to such a research and give, here below, six experimental ideas. 1 Ants could be collectively trained (as in the present work), then individually tested in front of the correct and wrong sequences. This would allow observing and perhaps assessing their individual behavior, giving ideas on how they proceed for learning the sequence. 2 It could be tempted to train ants to sequences made of 5, 6, 7, 8 elements for approaching the frontiers of their serial recognition learning. 
3 Assessing separately the response of young, middle aged and old ants in such experiments may bring some information on the topic, since middle aged ants are more able to acquire conditioning than younger and older ones (Cammaerts and Gosset, 2014). 4 The provided sequence could be inversely oriented, i.e. the last element being no longer aside the nest or the sugar water tube entrance, but located on the ants' foraging area (what is another kind of reward). 5 The provided sequence could be set between the nest entrance and the food site(s), and not at all next to any of these two kinds of reward. The ants moving along such a located sequence would thus no longer be directly rewarded though seeing it many times, and being thus susceptible to memorize it. 6 Of course, other ant species, as well as other social hymenoptera, should be experimented for enlarging our knowledge on the subject.

\section{Conclusion}

Ants (at least the species M. sabuleti) can learn to distinguish a given sequence made of 3 or 4 elements from others made of the same elements, but differently ordered, thanks to operant conditioning, i.e. being rewarded in presence of that given sequence, and retaining thus better the element directly associated with the reward. This is only a first step in our understanding of the ants' serial recognition and the underlying neuronal processes. As a matter of fact, future promising works could be performed for approaching the invertebrates as well as the vertebrates' serial recognition ability and the mechanism(s) underlying such ability.

\section{References}

Balleine, B. W., Garner, C., Gonzalez, F., \& Dickinson, A. (1995). Motivational control of heterogeneous instrumental chains. Journal of Experimental Psychology: Animal Behavior Processes, 21, 203-217. Retrieved from http://psycnet.apa.org/record/1995-35848-001

Cammaerts, M. C. (2007). Colour vision in the ant Myrmica sabuleti MEINERT, 1861 (Hymenoptera: Formicidae). Myrmecological News, 10, 41-50. Retrieved from https://myrmecologicalnews.org $). .$. Online version (PDFs)

Cammaerts, M. C. (2008). Visual discrimination of cues differing as for their number of elements, their shape or their orientation, by the ant Myrmica sabuleti. Biologia, 63, 1169-1180. Retrieved from https://link.springer.com/article/10.2478/s11756-008-0172-2

Cammaerts, M.-C. (2017a). Ants' ability in solving simple problems. International Journal of Biology, 9(3), 26-37. https://doi.org/10.5539/ijb.v9n3p26

Cammaerts, M.-C. (2017b). In a novel situation, ants can learn to react as never before - a preliminary study. Journal of Behavior, 2(2), 1011. Retrieved from https://www.jscimedcentral.com/Behavior/behavior-2-1011. php

Cammaerts, M.-C. (2018a). Can Myrmica rubra ants use tools or learn to use them? International Journal of Biology, 10(1). https://doi.org/10.5539/ijb.v10n1p1

Cammaerts, M.-C. (2018b). Learning a behavioral sequence: an accessible challenge for Myrmica sabuleti workers? International Journal of Biology, 10(2). https://doi.org/10.5539/ijb.v10n2p1

Cammaerts, M.-C., \& Cammaerts, D. (2014). Comparative outlook over three Myrmica species' biotopes and foragers' know-how. Biologia, 69, 1051-1058. Retrieved from https://link.springer.com/article/10.2478/ s11756-014-0399-z

Cammaerts, M.-C., \& Cammaerts, R. (2015). Ontogenesis of ants' cognitive abilities (Hymenoptera, Formicidae). Advanced Studies in Biology, 7, 335-348 + synopsis: 349-350. http://dx.doi.org/10.12988/asb.2015.54241

Cammaerts, M.-C., \& Cammaerts, R. (2016a). Spatial expectation of food location in an ant on basis of previous food locations (Hymenoptera, Formicidae). Journal of Ethology, 35(1), 9p, https://doi.org/10.1007/s10164 $-016-0494-4$.

Cammaerts, M.-C., \& Cammaerts, R. (2016b). Ants can expect the time of an event on basis of previous experiences. ISRN Entomology, Article ID 9473128. https://doi.org//10.1155/2016/9473128

Cammaerts, M.-C., \& Gosset, G. (2014). Impact of age, activity and diet on the conditioning performance in the ant Myrmica ruginodis used as a biological model. International Journal of Biology, l6(2), 10-20.

Castro C. A. (1995). Primacy and recency effects in rhesus monkeys (Macaca mulatta) using a serial probe recognition task I. Effects of diazepam. Psychopharmacology, 119(4), 421-427. Retrieved from https://ink.springer.com/article/10.1007/BF02245858

Castro, C. A. (1997). Primacy and recency effects in rhesus monkeys (Macaca mulatta) using a serial probe recognition task: II. Effects of atropine sulfate. Behavioral Neuroscience, 111(4), 676-682. http://dx.doi.org/10.1037/0735-7044.111.4.676 
Collett, T. S., Fry, S. N., \& Wehner, R. (1993). Sequence learning by honeybees. Journal of Comparative Physiology A, 172(6), 693-706. Retrieved from https://link.springer.com/article/10.1007/BF00195395

Farrell, S., \& McLaughlin, K. (2007). Short-term recognition memory for serial order and timing. Memory \& Cognition, 35(7), 1724-1734. Retrieved from https://link.springer.com/article/10.3758/BF03193505

Hölldobler, B., \& Wilson, E.O. (1990). The ants. Berlin. Springer Verlag. Retrieved from www.springer.com/gp/ book/9783540520924

Macquart, D., Latil, G., \& Beugnon, G. (2008). Sensorimotor sequence learning in the ant Gigantiops destructor. Animal Behavior, 75(5), 1693-1701. https://doi.org/10.1016/j.anbehav.2007.10.023

Monnier, C., \& Syssau A. (2008). Semantic contribution to verbal short-term memory: are pleasant words easier to remember than neutral words in serial recall and serial recognition? Memory \& Cognition, 36(1), 35-42. Retrieved from https://link.springer.com/article/10.3758/MC.36.1.35

Passera, L., \& Aron, S. (2005). Les fourmis: comportement, organisation sociale et évolution. Ottawa, Canada, Les Presses Scientifiques du CNRC. Retrieved from https://books.google.be/books?isbn=066097021X

Pearce, J. M. (2008). Animal learning and cognition, an introduction. East Sussex, USA, Canada. Psychology Press. Retrieved from http://www.worldcat.org/title/animal-learning-cognition-an-introduction/oclc/68222 3995

Roitblat, H. L., Bever, T. G., Helweg, D. A., \& Harley, H. E. (1991). On-line choice and representation of serially structured stimuli. Journal of experimental Psychology: animal behavior processes, 17, 55-67. Retrieved from http://psycnet.apa.org/record/1991-11848-001

Sands, S. F., \& Wright, A. A. (1980). Serial probe recognition performance by a rhesus monkey and a human with 10- and 20-item lists. Journal of Experimental Psychology: Animal Behavior Processes, 6(4), 386-396. http://dx.doi.org/10.1037/0097-7403.6.4.386

Siegel, S., \& Castellan, N. J. (1989). Nonparametric statistics for the behavioural sciences. Singapore, McGraw-Hill Book Company. Retrieved from https://www.amazon.com/Sidney-Siegel...Statistics.../ B008WDIR6...

Terrace, H. S. (1986). A nonverbal organism's knowledge of ordinal position in a serial learning task. Journal of experimental Psychology: animal behavior processes, 12, 202-214. https://doi.org/10.1037/0097-7403.12.3.203

Weisman, R. G., Wasserman, E. A., Dodd, P. W. D., \& Larew, M. B. (1980). Representation and retention of two-event sequences in pigeons. Journal of experimental Psychology: animal behavior processes, 6, 312-325. Retrieved fom scholar.google.com/citations?user=aodwfA8AAAAJ\&hl=en

Wright, A. A., Santiago, H. C., Sands, S. F., Kendrick, D. F., \& Cook, R. G. (1985). Memory processing of serial lists by pigeons, monkeys, and people. Science, 229, 287-289. Retrieved from https://d2ufo47lrtsv5s. cloudfront.net/content/229/.../tab-article-inf...

\section{Copyrights}

Copyright for this article is retained by the author(s), with first publication rights granted to the journal.

This is an open-access article distributed under the terms and conditions of the Creative Commons Attribution license (http://creativecommons.org/licenses/by/4.0/). 